\title{
Strategi Pemasaran Digital dalam Peningkatan Penerimaan Mahasiswa Baru Menggunakan Analisis SWOT
}

\author{
Titus Kristanto ${ }^{1}$, Walid Maulana Hadiansyah ${ }^{2}$, Muhammad Nasrullah ${ }^{\mathbf{3}}$, Amanda Amalia ${ }^{\mathbf{1}}$, \\ Erlin Yuli Anggraini ${ }^{2}$, Ainurrohman Firmansyah ${ }^{4}$ \\ ${ }^{1}$ Program Studi Rekayasa Perangkat Lunak, Institut Teknologi Telkom Surabaya \\ ${ }^{2}$ Program Studi Teknik Telekomunikasi, Institut Teknologi Telkom Surabaya \\ ${ }^{3}$ Program Studi Sistem Informasi, Institut Teknologi Telkom Surabaya \\ ${ }^{4}$ SMK Nuris Jember \\ titus.kristanto@ittelkom-sby.ac.id, walid@ittelkom-sby.ac.id, emnasrul@ittelkom-sby.ac.id, \\ amanda@student.ittelkom-sby.ac.id, erlinyuli@student.ittelkom-sby.ac.id, 41noer@gmail.com
}

Diterima : 8 November 2020. Disetujui : 5 Desember 2020. Dipublikasikan : 6 Desember 2020.

\begin{abstract}
Higher education is the highest educational institution in educating and educating the nation's children to become leaders in the future. To prepare the nation's children, universities are intended to produce quality and beneficial innovations for the country. One of the innovations made by higher education institutions is to make strategies in getting new students both in quality and quantity. In one of the private universities (PTS XYZ) in the city of Surabaya, there has been a decrease in new students for the last 5 years (2015-2020). In order not to experience a decline in new students, PTS XYZ makes an interesting strategy so that new student admissions can be as maximum as possible. The approach used in this research is the SWOT analysis. The research objective of using SWOT analysis is to determine internal environmental factors and external environmental factors which are strengths, weaknesses, opportunities, and threats in digital marketing. The method used in this research is the method of observation, survey, interview, and questionnaire. The result of research using SWOT analysis is to increase new student admissions, so that it can increase the reputation of the college and optimize digital marketing.
\end{abstract}

Keywords: strategic, digital marketing, new students, swot analysis

Abstrak-Perguruan tinggi merupakan lembaga pendidikan tertinggi dalam mendidik dan mencerdaskan anak bangsa agar menjadi pemimpin di masa depan. Untuk mempersiapkan anak bangsa, perguruan tinggi dituntuk untuk menghasilkan inovasi yang berkualitas dan bermanfaat bagi Negeri. Salah satu inovasi yang dilakukan perguruan tinggi adalah membuat strategi dalam mendapatkan mahasiswa baru baik secara kualitas maupun kuantitas. Pada salah satu perguruan tinggi swasta (PTS XYZ) di Kota Surabaya mengalami penurunan mahasiswa baru selama 5 tahun terakhir (2015-2020). Agar tidak mengalami penurunan mahasiswa baru, maka PTS XYZ membuat strategi yang menarik agar penerimaan mahasiswa baru dapat semaksimal mungkin. Pendekatan yang digunakan dalam penelitian adalah Analisis SWOT. Adapun tujuan penelitian menggunakan Analisis SWOT adalah untuk mengetahui faktor lingkungan internal dan faktor lingkungan eksternal yang menjadi kekuatan, kelemahan, peluang, dan ancaman dalam pemasaran digital. Metode yang digunakan dalam penelitian adalah metode observasi, survey, wawancara, dan kuesioner. Hasil penelitian menggunakan Analisis SWOT adalah meningkatkan penerimaan mahasiswa baru, sehingga dapat meningkatkan reputasi perguruan tinggi dan mengoptimalkan pemasaran digital.

Kata Kunci: pemasaran digital, mahasiswa baru, analisis swot

\section{PENDAHULUAN}

Perguruan tinggi merupakan lembaga Pendidikan tertinggi dengan tujuan mendidik anak bangsa menjadi pemimpin di masa depan. Untuk mempersiapkan anak bangsa, perguruan tinggi dituntut mampu menghasilkan inovasi yang berkualitas [1].

Persaingan dalam dunia Pendidikan khususnya perguruan tinggi tidak dapat terelakkan lagi dalam memperoleh pangsa pasar mahasiswa semakin ketat [2]. Hal tersebut, banyak perguruan tinggi swasta bermuncul bagaikan "Jamur yang hidup di musim hujan" [3]. Bagi perguruan tinggi baru dan belum dikenal, mengalami dampak persaingan dalam mendapatkan mahasiswa. Berbagai macam strategi yang dilakukan adalah perang strategi perguruan tinggi dalam mendapatkan mahasiswa baru baik secara kualitas dan kuantitas. Sehingga setiap perguruan tinggi mempunyai strategi yang menarik 
agar penerimaan mahasiswa baru dapat semaksimal mungkin. Strategi tersebut dibuat berdasarkan hasil situasi dan kondisi yang dihadapi, baik situasi eksternal maupun situasi internal [4].

Analisis dilakukan berdasarkan pada orientasi kebutuhan dan keinginan mahasiswa baru yakni Analisis SWOT [5]. Analisis SWOT merupakan analisis pada strength (kekuatan), weakness (kelemahan), opportunities (kesempatan), dan threats (tantangan) yang dihadapi perguruan tinggi secara eksternal maupun internal [6].

Permasalahan internal yang dihadapi berupa kekuatan dan kelemahan pada perguruan tinggi tersebut. Misal, masalah sumber daya. Permasalahan internal dapat diatasi berupa layanan pendidikan, biaya yang dikeluarkan mahasiswa, promosi, dan lokasi kampus [7]. Sedangkan permasalahan eksternal, berupa peluang dan ancaman dengan bermunculan perguruan tinggi baru. Pada Gambar 1 grafik penurunan mahasiswa baru 5 tahun terakhir (2015-2020) [3].

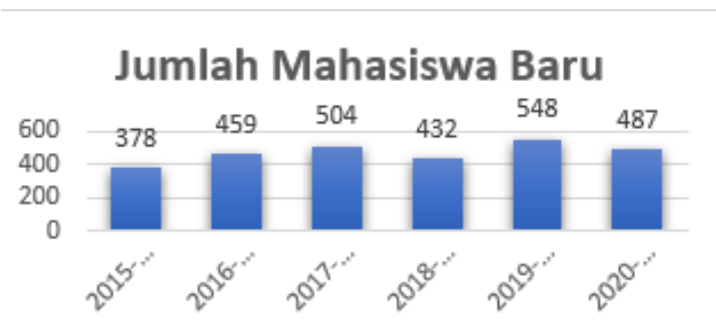

Gambar 1. Jumlah Mahasiswa Baru

Pada beberapa tahun terakhir, jumlah penerimaan mahasiswa baru mengalami penurunan, diakibatkan pengaturan kuota pada PTN tidak teratur. Kecenderungan penurunan mahasiswa baru, membuat perguruan tinggi mengambil kebijakan terkait daya minat calon mahasiswa baru. Diperlukan sumber daya yang dapat berperan aktif dalam mencerdaskan kehidupan bangsa dan negara sesuai amanah UndangUndang.

Untuk mengetahui situasi dan kondisi pada perguruan tinggi diperlukan penyusunan rencana perbaikan strategi. Analisis situasi dan kondisi meliputi lingkungan eksternal dan internal pada perguruan tinggi.

Analisis pada lingkungan eksternal berupa kuesioner kepada pihak luar. Sasaran yakni siswasiswa SMA/SMK Kelas XII, calon mahasiswa gagal kuliah di PTN, dan orang tua calon mahasiswa baru. Ada beberapa jawaban dari kuesioner sebagai pandangan pihak luar terhadap perguruan tinggi yakni [8] :

1. Status akreditasi.

2. Lokasi kampus.

3. Jalur alih jenjang
4. Jalur profesional.

5. Biaya kuliah.

6. Jam kuliah pagi-sore hari.

7. Jam kuliah sore-malam hari.

8. Kurang informasi.

9. Lulusan.

10. Program studi tidak sesuai.

11. Promosi

12. Tidak berminat.

Pada Gambar 2, respon tanggapan pihak luar terkait analisis lingkungan eksternal.

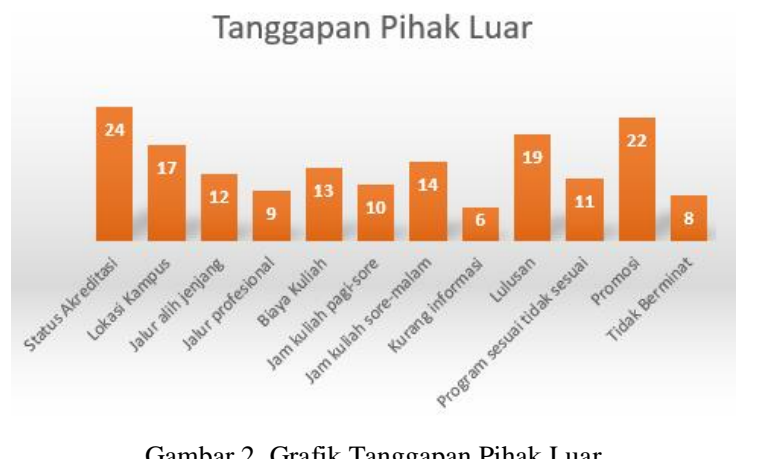

Pada analisis lingkungan internal berupa kuesioner yang ditujukan kepada mahasiswa internal perguruan tinggi. Ada beberapa pertanyaan berupa aspek layanan mahasiswa yakni [9] :

1. Ruang kuliah.

2. Suasana perkuliahan.

3. Informasi perkuliahan

4. Mata kuliah up-to-date.

5. Materi perkuliahan up-to-date.

6. Kesesuaian RPP dan Silabus.

7. Dosen pengampu.

8. Cara mengajar dosen.

9. Ruang perpustakaan.

10. Koleksi buku perpustakaan.

11. Pelayanan akademik.

12. Pelayanan kemahasiswaan.

13. Pelayanan perpustakaan

14. Informasi jadwal kuliah/ujian.

15. Informasi nilai mata kuliah.

16. Unit kegiatan mahasiswa.

17. Akses internet.

18. Akses e-learning.

19. Fasilitas Laboratorium.

20. Fasilitas olahraga.

21. Fasilitas keagamaan.

Pada Gambar 3 merupakan permasalahan yang terjadi pada aspek layanan mahasiswa. Permasalahan yang terjadi pada fasilitas di kampus dan pelayanan terhadap mahasiswa.

Selain faktor dari lingkungan eksternal dan internal perguruan tinggi, terdapat faktor kesempatan 
dan tantangan yang mempengaruhi pada penerimaan mahasiswa baru.

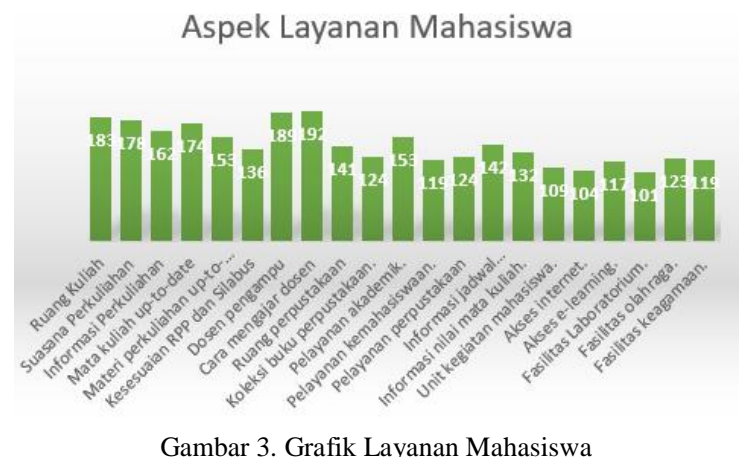

1) Tantangan

Banyak perusahaan menyerap lulusan SMA/SMK bekerja pada tingkat operator.

Untuk menghadapi kesempatan dan tantangan yang terjadi, maka perguruan tinggi membutuhkan strategi dalam penerimaan mahasiswa baru yaitu [10]

a. Sosialisasi perguruan tinggi baik melalui online ataupun datang ke sekolah-sekolah SMA/SMK.

b. Mengikuti kegiatan expo kampus.

c. Memasang spanduk, poster, baliho di tempattempat strategis.

d. Menyelenggarakan acara seminar/workshop baik untuk siswa ataupun guru SMA/SMK.

\section{METODE PENELITIAN}

Pada Gambar 4 merupakan gambaran metode penelitian. Penelitian ini berfokus pada permasalahan pemasaran yang berada di salah satu perguruan tinggi swasta di Kota Surabaya. Waktu penelitian dilakukan pada rentang tahun 2015-2020. Obyek pada penelitian merupakan mahasiswa baru angkatan 2020/2021 [10].

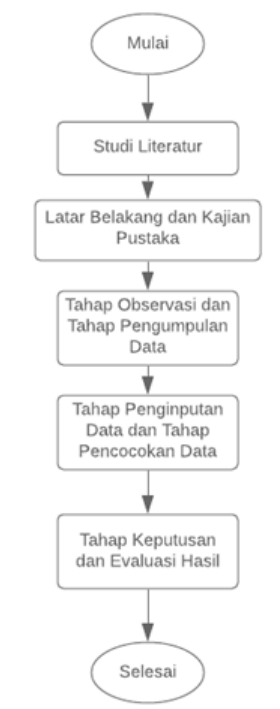

Gambar 4. Metode Penelitian
Ada empat tahap yang dilakukan pada penelitian yaitu [11] :

1. Tahap Observasi

Pada tahap observasi berupa tahap identifikasi permasalahan dan menganalisis permasalahan yang ada di perguruan tinggi.

2. Tahap Pengumpulan Data

Pada tahap pengumpulan data berupa data primer dan data sekunder. Data primer didapatkan dari hasil wawancara, survey, dan pengisian kuesioner yang diperoleh dari calon mahasiswa baru dan mahasiswa aktif. Data sekunder diambilkan dari data jumlah penerimaan mahasiswa baru 5 tahun terakhir (2015-2020).

3. Tahap Penginputan Data

Pada tahap penginputan data dilakukan bertujuan untuk mengetahui dan mengidentifikasi dari faktor internal (kekuatan dan kelemahan) dan faktor ekternal (peluang dan ancaman) yang berpengaruh pada penerimaan mahasiswa baru.

4. Tahap Pencocokan Data

Pada tahap pencocokan data menggunakan Analisis SWOT. Input dari Analisis SWOT berasal dari hasil kuesioner yang sudah diisi.

5. Tahap Keputusan

Pada tahap keputusan dibuat berdasarkan penetapan dari beberapa strategi oleh perguruan tinggi. Hasil dari Analisis SWOT berupa strategi kebijakan yang disusun pada kuesioner.

\section{HASIL DAN PEMBAHASAN}

\section{A. Analisis Faktor Lingkungan Internal dan Eksternal}

Berdasarkan hasil dari identifikasi faktor lingkungan internal dan faktor lingkungan eksternal yang dihadapi PTS XYZ kepada siswa yang berpotensial, maka diperlukan strategi pemasaran digital menggunakan Analisis SWOT pada penerimaan mahasiswa baru, maka dapat dirumuskan sebagai berikut [12]:

1. Faktor Lingkungan Internal

a. Faktor Kekuatan (Strength)

- Akses internet dapat dijangkau secara luas.

- Pemasaran digital dapat mencakup seluruh kota/kabupaten di seluruh Indonesia.

- Dapat diakses selama 24 jam

- Biaya pemasaran yang dikeluarkan lebih terjangkau.

- Mendapatkan umpan balik secara instan.

- Dapat menghemat waktu.

b. Faktor Kelemahan (Weakness)

- Biaya pemasaran digital sangat tinggi.

- Masih ada menggunakan pemasaran secara offline. 
- Masih ada pelanggan belum tersedia internet.

- Masih ada pelanggan belum terbiasa menggunakan internet.

- Adanya kesalahan teknis.

- Rentan adanya tindak penipuan.

2. Faktor Lingkungan Eksternal

a. Faktor Peluang (Opportunity)

- Adanya promosi/diskon khusus.

- Mempunyai media pemasaran digital.

- Didukung penuh oleh teknologi informasi (IT).

- Jaringan internet berkembang pesat.

- Adanya pendampingan dan pelatihan pemasaran digital.

- Adanya rencana pengembangan pemasaran digital.

b. Faktor Ancaman (Threat)

- Adanya kompetitor tumbuh dan berkembang secara cepat.

- Jumlah produk yang dipasarkan monoton.

- Adanya pengeluaran tidak terduga.

- Pelanggan peka terhadap biaya pendidikan.

- Hasil survei kepuasan pelanggan masih rendah.

- Inovasi dari produk yang dipasarkan masih sedikit.

Berdasarkan hasil dari faktor lingkungan internal menggunakan Analisis SWOT pada Tabel I, dapat disimpulkan bahwa kekuatan utama adalah Akses internet dapat dijangkau secara luas dengan bobot skor sebesar 0,572 [13]. Sedangkan kelemahan utama adalah Biaya awal mula pemasaran digital sangat tinggi dengan dengan bobot skor sebesar $\mathbf{0 , 3 2 4}$. Jadi total skor sebesar $\mathbf{2 , 8 9 3}$ menunjukkan rata-rata kondisi internal [14].

TABEL I. HASIL PEMBOBOTAN PADA FAKTOR LINGKUNGAN INTERNAL

\begin{tabular}{|l|l|c|c|c|}
\hline No & \multicolumn{1}{|c|}{ Faktor } & Bobot & Rating & $\begin{array}{c}\text { Skor } \\
\text { Terbobot }\end{array}$ \\
\hline Kekuatan & $\begin{array}{l}\text { | } \\
\mathrm{S}_{1}\end{array} \begin{array}{l}\text { Akses internet } \\
\text { dapat dijangkau } \\
\text { secara luas }\end{array}$ & 0,143 & 4 & 0,572 \\
\hline $\mathrm{S}_{2}$ & $\begin{array}{l}\text { Pemasaran digital } \\
\text { dapat mencakup } \\
\text { seluruh } \\
\text { kota/kabupaten di } \\
\text { seluruh Indonesia }\end{array}$ & 0,132 & 4 & 0,528 \\
\hline $\mathrm{S}_{3}$ & $\begin{array}{l}\text { Dapat diakses } \\
\text { selama 24 jam }\end{array}$ & 0,136 & 4 & 0,544 \\
\hline $\mathrm{S}_{4}$ & $\begin{array}{l}\text { Biaya pemasaran } \\
\text { yang dikeluarkan } \\
\text { lebih terjangkau }\end{array}$ & 0,058 & 3 & 0,174 \\
\hline $\mathrm{S}_{5}$ & $\begin{array}{l}\text { Mendapatkan } \\
\text { umpan balik secara } \\
\text { instan }\end{array}$ & 0,051 & 3 & 0,153 \\
\hline $\mathrm{S}_{6}$ & $\begin{array}{l}\text { Dapat menghemat } \\
\text { waktu }\end{array}$ & 0,052 & 3 & 0,156 \\
\hline
\end{tabular}

\begin{tabular}{|c|c|c|c|c|}
\hline No & Faktor & Bobot & Rating & $\begin{array}{c}\text { Skor } \\
\text { Terbobot }\end{array}$ \\
\hline \multicolumn{5}{|c|}{ Kelemahan } \\
\hline $\mathrm{W}_{1}$ & $\begin{array}{lr}\text { Biaya } & \text { pemasaran } \\
\text { digital } & \text { sangat } \\
\text { tinggi } & \end{array}$ & 0,121 & 2 & 0,324 \\
\hline $\mathrm{W}_{2}$ & $\begin{array}{l}\text { Masih ada } \\
\text { menggunakan } \\
\text { pemasaran secara } \\
\text { offline }\end{array}$ & 0,101 & 2 & 0,316 \\
\hline $\mathrm{W}_{3}$ & $\begin{array}{l}\text { Masih ada } \\
\text { pelanggan belum } \\
\text { tersedia internet }\end{array}$ & 0,116 & 2 & 0,298 \\
\hline $\mathrm{W}_{4}$ & $\begin{array}{l}\text { Masih ada } \\
\text { pelanggan belum } \\
\text { terbiasa } \\
\text { menggunakan } \\
\text { internet }\end{array}$ & 0,042 & 1 & 0,054 \\
\hline $\mathrm{W}_{5}$ & $\begin{array}{l}\text { Adanya kesalahan } \\
\text { teknis }\end{array}$ & 0,031 & 1 & 0,031 \\
\hline $\mathrm{W}_{6}$ & $\begin{array}{l}\text { Rentan adanya } \\
\text { tindak penipuan }\end{array}$ & 0,017 & 1 & 0,027 \\
\hline & Total & 1,000 & & 2,893 \\
\hline
\end{tabular}

Berdasarkan hasil dari faktor lingkungan eksternal menggunakan Analisis SWOT pada Tabel II, dapat disimpulkan bahwa peluang utama adalah Didukung penuh oleh teknologi informasi (IT) dengan bobot skor sebesar 0,836 [15]. Sedangkan ancaman yang dihadapi adalah Adanya pengeluaran tidak terduga dengan bobot skor sebesar 0,216 [16].

TABEL II. HASIL PEMBOBOTAN PADA FAKTOR LINGKUNGAN EKSTERNAL

\begin{tabular}{|c|c|c|c|c|}
\hline No & Faktor & Bobot & Rating & $\begin{array}{c}\text { Skor } \\
\text { Terbobot }\end{array}$ \\
\hline \multicolumn{5}{|c|}{ Peluang } \\
\hline $\mathrm{O}_{1}$ & $\begin{array}{l}\text { Mempunyai media } \\
\text { pemasaran digital }\end{array}$ & 0,203 & 4 & 0,812 \\
\hline $\mathrm{O}_{2}$ & $\begin{array}{l}\text { Didukung penuh } \\
\text { oleh teknologi } \\
\text { informasi (IT) }\end{array}$ & 0,209 & 4 & 0,836 \\
\hline $\mathrm{O}_{3}$ & $\begin{array}{l}\text { Adanya } \\
\text { promosi/diskon } \\
\text { khusus }\end{array}$ & 0,101 & 3 & 0,303 \\
\hline $\mathrm{O}_{4}$ & $\begin{array}{l}\text { Jaringan internet } \\
\text { berkembang pesat }\end{array}$ & 0,102 & 3 & 0,306 \\
\hline $\mathrm{O}_{5}$ & $\begin{array}{l}\text { Adanya } \\
\text { pendampingan dan } \\
\text { pelatihan } \\
\text { pemasaran digital }\end{array}$ & 0,022 & 2 & 0,044 \\
\hline $\mathrm{O}_{6}$ & $\begin{array}{l}\text { Adanya rencana } \\
\text { pengembangan } \\
\text { pemasaran digital }\end{array}$ & 0,011 & 1 & 0,011 \\
\hline \multicolumn{5}{|c|}{ Ancaman } \\
\hline $\mathrm{T}_{1}$ & $\begin{array}{l}\text { Kompetitor } \\
\text { tumbuh dan } \\
\text { berkembang secara } \\
\text { cepat }\end{array}$ & 0,102 & 2 & 0,204 \\
\hline $\mathrm{T}_{2}$ & $\begin{array}{l}\text { Adanya } \\
\text { pengeluaran tidak } \\
\text { terduga }\end{array}$ & 0,108 & 2 & 0,216 \\
\hline $\mathrm{T}_{3}$ & $\begin{array}{lr}\text { Pelanggan } & \text { peka } \\
\text { terhadap } & \text { biaya } \\
\text { pendidikan } & \end{array}$ & 0,101 & 2 & 0,202 \\
\hline
\end{tabular}




\begin{tabular}{|c|l|c|c|c|}
\hline No & \multicolumn{1}{|c|}{ Faktor } & Bobot & Rating & $\begin{array}{c}\text { Skor } \\
\text { Terbobot }\end{array}$ \\
\hline $\mathrm{T}_{4}$ & $\begin{array}{l}\text { Jumlah produk } \\
\text { yang dipasarkan } \\
\text { monoton }\end{array}$ & 0,017 & 1 & 0,017 \\
\hline $\mathrm{T}_{5}$ & $\begin{array}{l}\text { Hasil survei } \\
\text { kepuasan } \\
\text { pelanggan masih } \\
\text { rendah }\end{array}$ & 0,013 & 1 & 0,013 \\
\hline $\mathrm{T}_{6}$ & $\begin{array}{l}\text { Inovasi dari produk } \\
\text { yang dipasarkan } \\
\text { masih sedikit }\end{array}$ & 0,011 & 1 & 0,011 \\
\hline \multicolumn{2}{|c|}{ Total } & $\mathbf{1 , 0 0 0}$ & & $\mathbf{2 , 9 7 5}$ \\
\hline
\end{tabular}

\section{B. Matriks SWOT}

Matriks SWOT merupakan tahapan yang harus dilakukan oleh PTS XYZ dalam menghadapi peluang dan ancaman yang dihadapi, serta untuk mengetahui kekuatan dan kelemahan yang dimiliki oleh PTS XYZ. Analisis SWOT menghasilkan empat perspektif strategi yaitu S-O (Strength-Opportunities), W-O (Weakness-Opportunities), S-T (StrenghtThreats), dan W-T (Weakness-Threats). Pada Tabel III, merupakan strategi yang dihasilkan dari Matris SWOT [12].

TABEL III. HASIL MATRIKS SWOT

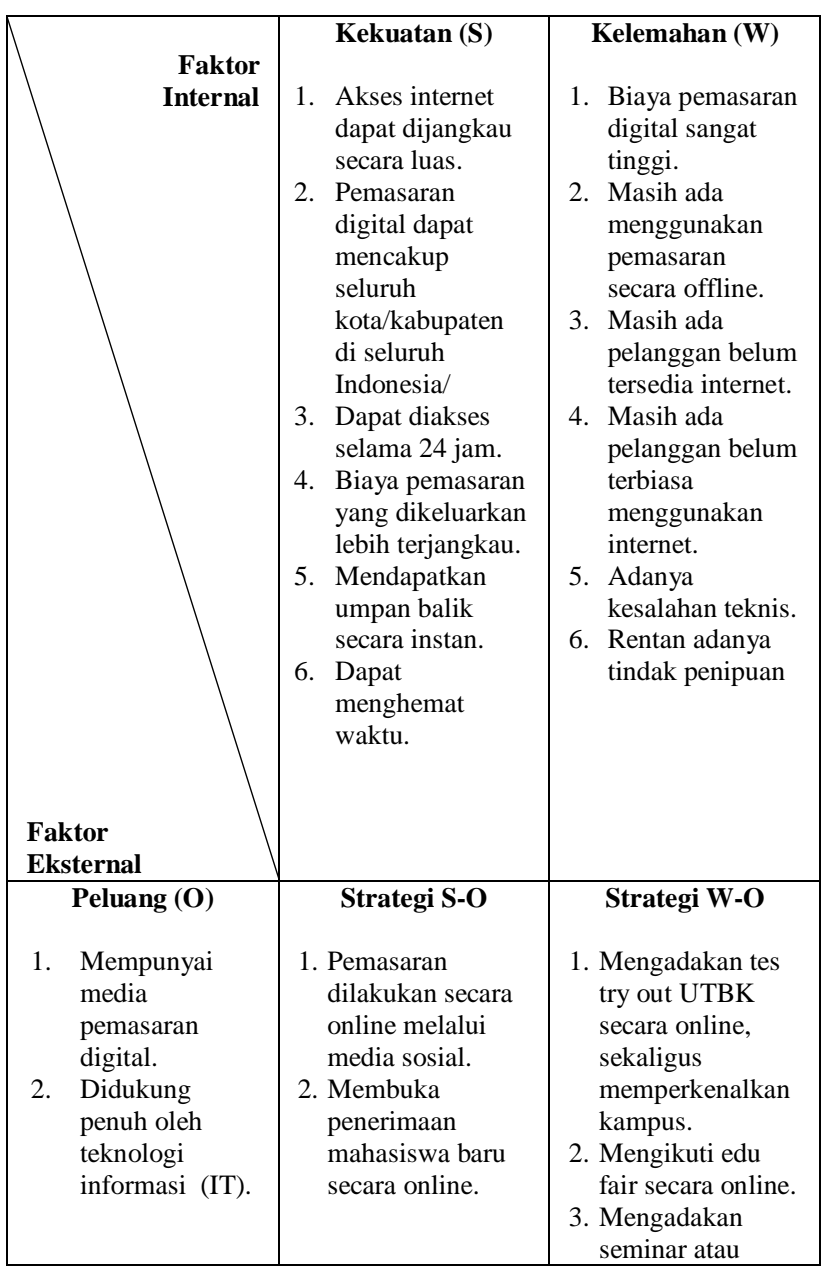

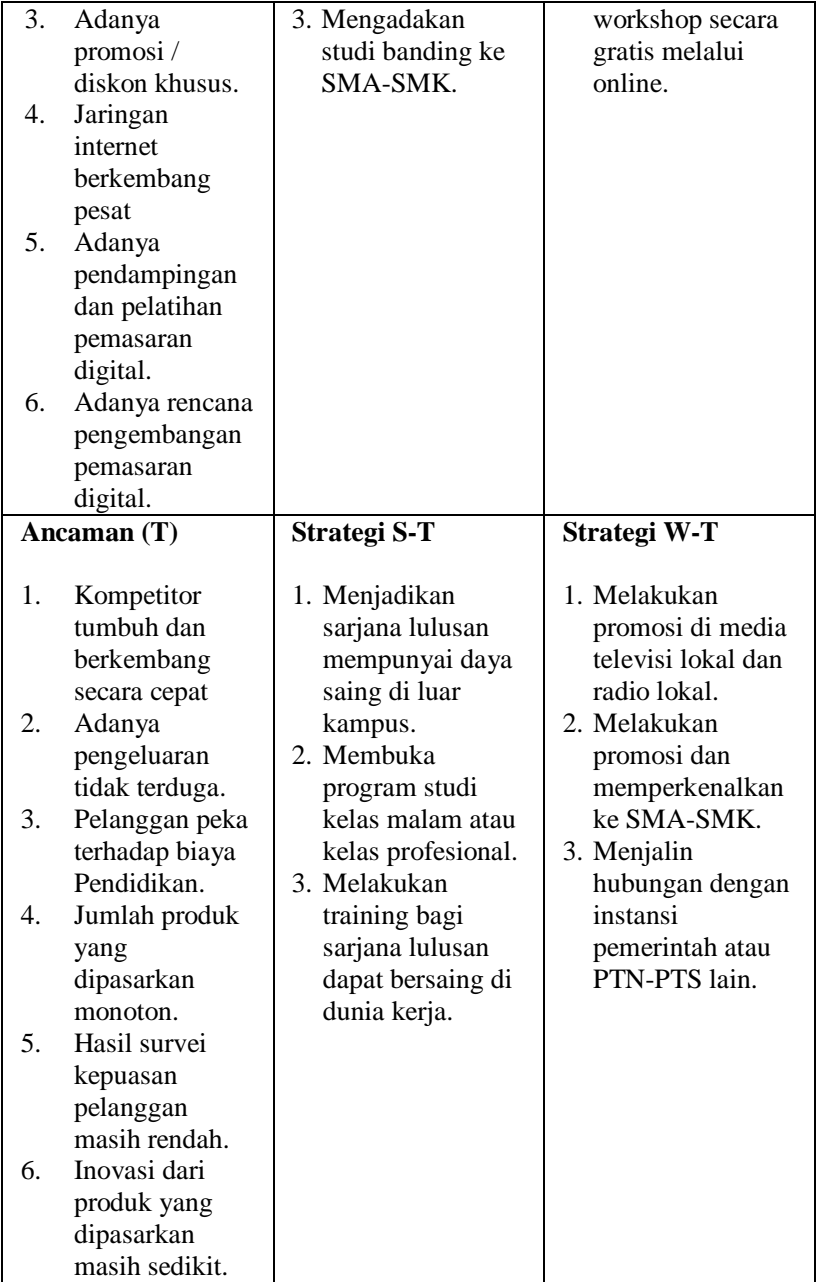

Berdasarkan hasil dari Matriks SWOT pada

Tabel III, didapatkan 12 alternatif strategi, diantaranya:

1. Pemassaran dilakukan secara online melalui media sosial.

2. Membuka penerimaan mahasiswa baru secara online.

3. Mengadakan studi banding ke SMA-SMK.

4. Mengadakan tes try out UTBK secara online, sekaligus memperkenalkan kampus.

5. Mengikuti edu fair secara online.

6. Mengadakan seminar atau workshop secara gratis melalui online.

7. Menjadikan sarjana lulusan mempunyai daya saing di luar kampus.

8. Membuka program studi kelas malam atau kelas professional.

9. Melakukan training bagi sarjana lulusan dapat bersaing di dunia kerja.

10. Melakukan promosi di media televisi lokal dan radio lokal.

11. Melakukan promosi dan memperkenalkan ke SMA-SMK.

12. Menjalin hubungan dengan instansi pemerintah atau PTN-PTS lain. 


\section{KESIMPULAN DAN SARAN}

Penelitian ini difokuskan pada strategi PTS XYZ dalam meningkatkan pangsa pasar melalui media online dengan cata membidik siswa-siswi kelas XII SMA-SMK yang mempunyai potensial. PTS XYZ juga menjalin hubungan baik anatara instansi pemerintah atau PTN-PTS lain. PTS XYZ membuat beberapa inovasi terbaru bagi masyarakat yang mempunyai daya saing tinggi dan PTS XYZ juga memanfaatkan teknologi informasi (IT) dalam pemasaran digital.

Tim peneliti memberi beberapa masukan terkait penelitian yang dapat dikemudian hari diantaranya membuka pangsa dan membidik pasar ke Wilayah Indonesiam Timur sebagai kemudahan dalam pendaftaran mahasiswa baru secara online dan menciptakan Positioning dan Branding. Maksud dari Positioning adalah memperkuat PTS XYZ pada akreditasi institusi minimal "Baik" oleh BAN-PT. Selain menciptakan Positioning, didukung Branding yang kuat, termasuk branding image PTS XYZ.

\section{UCAPAN TERIMA KASIH}

Tim peneliti mengucapkan terima kasih kepada Deputi Bidang Penguatan Riset dan Pengembangan Kementerian Riset dan Teknologi/Badan Riset dan Inovasi Nasional (RistekBrin) yang sudah membiayai kegiatan Hibah Penelitian Dosen Pemula (PDP) Tahun Anggaran 2020. Tim peneliti tidak lupa mengucapkan terima kasih juga pada LPPM ITTelkom Surabaya yang sudah mendukung kegiatan Penelitian Dosen Pemula (PDP) Tahun 2020.

\section{REFERENSI}

[1] A. Fauzan, "Evaluasi Kinerja Perguruan Tinggi Islam Berbasis Balanced Scorecard," Al-Idarah J. Kependidikan Islam, vol. 6, no. 2, pp. 81-99, 2016.

[2] F. Karela, "Strategi Manajemen Pemasaran Dalam Peningkatan Penerimaan Peserta Didik Di Madrasah Tsanawiyah Mazra'atul Ulum Paciran Lamongan,” 2020.

[3] S. Dharmawansyah, H. Cangara, and M. I. Sultan,
"Strategi Promosi Dalam Meningkatkan Jumlah Mahasiswa Pada Politeknik Negeri Media Kreatif Makassar," KAREBA J. Ilmu Komun., vol. 3, no. 4, pp. 256-263, 2014.

[4] E. Sopandi, "Strategi Promosi Penerimaan Mahasiswa Baru Untuk PTS (Tinjauan Atas Kegiatan Promosi PTS di Jawa Barat Tahun 2010)," Manajerial J. Manaj. Dan Sist. Inf., vol. 10, no. 1, pp. 87-101, 2011.

[5] A. D. Triyana, Menerapkan Strategi Marekting di Indonesia. Jakarta: Marketing Seminars, 1987.

[6] T. Kristanto, E. C. Muliawati, R. Arief, and S. Hidayat, "Strategi Peningkatan Omset UKM Percetakan Dengan Pendekatan Analisis SWOT," in Seminar Nasional Sistem Informasi Infonesia (SESINDO) 2017, 2017.

[7] A. Dharmawan Salim, "IMC: Promosi, Iklan, dan Sponsor Rokok Strategi Perusahaan Menggiring Remaja Untuk Merokok," BENEFIT J. Manaj. dan Bisnis, vol. 17 , no. 1 , pp. 58-65, 2013

[8] N. Rusdiana, H. Susanto, and Jamal, "Strategi Cyber Marketing Untuk Meningkatkan Jumlah Penerimaan Mahasiswa Baru,” Energy, vol. 8, no. 2, pp. 22-28, 2018.

[9] T. Kristanto, A. T. Kurniawati, and T. L. Sugita, "Sistem Informasi Manajemen Proyek Video Editing Berbasis Web Menggunakan PRINCE2 Di Faia Art," Multinetics, vol. 5, no. 1, pp. 1-8, 2019.

[10] S. Nurdin and R. N. I. Dinnullah, "Analisis Penerimaan Mahasiswa Baru dengan Penentuan Strategi Keunggulan Bersaing," J. Ilm. Tek. Ind., vol. 16, no. 2, 2017.

[11] E. Setijadi, A. K. Darmawan, R. Mardiyanto, I. Santosa, Hoiriyah, and T. Kristanto, "A Model for Evaluation Smart City Readiness using Structural Equation Modelling: A Citizen's Perspective," in Proceedings of 2019 4th International Conference on Informatics and Computing, ICIC 2019, 2019.

[12] Fitriani and B. Suhada, "Strategi Pemasaran Universitas Muhammadiyah Metro," Derivatif, vol. 10, no. 2, pp. 19, 2016.

[13] P. Irfan and Apriani, "Analisa Strategi Pengembangan ETourism Sebagai Promosi Pariwisata Di Pulau Lombok," Ilk. J. Ilm., vol. 9, no. 3, pp. 325-330, 2017.

[14] H. K. Zia, R. Semiarty, and R. P. Lita, "Analisis SWOT Sebagai Penentu Strategi Pemasaran Pada Rumah Sakit Gigi Dan Mulut Baiturrahmah Padang," J. Kesehat. Andalas, vol. 7, no. Supplement 4, p. 6, 2018.

[15] O. Y. Yuliana, "Penggunaan Teknologi Internet Dalam Bisnis," J. Akunt. dan Keuang., vol. 2, no. 1, pp. 36-52, 2000.

[16] A. Hardiyanto, I. Soejanto, and I. Berlianty, "Analisis Strategi Pembangunan Desa Wisata Di Sentra Pengrajin Keris," Opsi J. Optimasi Sist. Ind., vol. 11, no. 1, p. 1, 2018. 